\title{
Expression of Syk and MAP4 proteins in ovarian cancer
}

\author{
Siwei Zhang ${ }^{1} \cdot$ Suha Deen $^{2} \cdot$ Sarah J. Storr ${ }^{1} \cdot$ Anqi Yao $^{1} \cdot$ Stewart G. Martin ${ }^{1}$
}

Received: 28 January 2019 / Accepted: 1 February 2019 / Published online: 8 February 2019

(c) The Author(s) 2019

\begin{abstract}
Purpose We have previously reported on the prognostic importance of the calpain family of proteins in ovarian cancer, especially calpain-2. Spleen tyrosine kinase (Syk) phosphorylates a variety of cytoskeletal proteins with studies suggesting potential interactions between Syk and conventional calpains. Microtubule-associated protein 4 (MAP4) has been reported to be regulated by Syk.

Methods The current study assessed Syk and MAP4 protein expression, by immunohistochemistry on a tissue microarray comprised of cores from primary ovarian carcinomas $(n=575)$, to evaluate associations with patient clinical outcomes and other clinicopathological factors and sought to determine whether there were any correlations between the expression of Syk, MAP4 and the calpain system.

Results MAP4 expression was significantly associated with ovarian cancer histological subtype $(P<0.001)$, stage $(P=0.001)$, grade $(P<0.001)$ and residual tumour $(P=0.005)$. Despite this finding, we found no significant association existing between MAP4 expression and overall survival. Syk expression was also found significantly associated with histological subtype $(P<0.001)$. Syk seems to play a contradictory role with respect to tumour progression: low cytoplasmic Syk expression was significantly associated with low stage $(P=0.013)$, and low nuclear Syk expression with chemo-resistance in patients treated with taxane-containing therapy $(P=0.006)$. Interestingly, despite the lack of association in the whole cohort, high nuclear Syk expression was significantly associated with better overall survival in certain subgroups $(P=0.001)$.

Conclusions The current study indicates a lack of correlation between calpain-2 expression and Syk and MAP4. Syk, MAP4 and calpain-1 appeared to significantly correlate with each other in the whole cohort, with calpain-1 being more highly associated with MAP4 and Syk in mucinous carcinomas. Overall, the current results suggest that Syk, MAP4, and calpain-1 expression are correlated with each other and these proteins may be involved in early stages of tumour spread.
\end{abstract}

Keywords MAP4 $\cdot$ Syk $\cdot$ Calpain $\cdot$ Calpastatin $\cdot$ Ovarian cancer $\cdot$ Chemotherapy

\section{Abbreviations}

MAP Microtubule-associated protein

Syk Spleen tyrosine kinase

Syk-c Cytoplasmic Syk

Syk-n Nuclear Syk

Electronic supplementary material The online version of this article (https://doi.org/10.1007/s00432-019-02856-9) contains supplementary material, which is available to authorized users.

Stewart G. Martin

stewart.martin@nottingham.ac.uk

1 Academic Clinical Oncology, Nottingham Breast Cancer Research Centre, School of Medicine, University of Nottingham, Nottingham University Hospitals NHS Trust, City Hospital Campus, Nottingham NG5 1PB, UK

2 Department of Pathology, Queen's Medical Centre, Nottingham University Hospital, Nottingham NG7 2UH, UK

\section{Introduction and aims}

The calpain system has been confirmed to play an important role in influencing ovarian cancer patient outcomes with the adverse association between high calpain-2 expression and worse overall survival in ovarian cancer (Storr et al. 2012) being recently verified, and with calpain- 4 and calpastatin expression also being found to be associated with overall survival (Zhang et al. 2018). However, the mechanisms whereby the calpain system exerts it important effects in ovarian cancer progression remain to be fully elucidated.

Spleen tyrosine kinase (Syk), a cytoplasmic nonreceptor tyrosine kinase (Baldock et al. 2000), is widely expressed in a variety of hematopoietic cells (Singh et al. 2012; Krisenko and Geahlen 2015) and has been detected in osteoclasts, normal and tumourigenic mammary epithelial cells, melanocytes, human nasal fibroblasts, 
hepatocytes, neuronal cells and vascular endothelial cells suggesting that Syk has a general physiological function in a wide variety of non-hematopoietic cells (Coopman and Mueller 2006; Yanagi et al. 2001; Singh et al. 2012). Syk has been reported as a pro-survival factor in many hematopoietic malignancies (Krisenko and Geahlen 2015) and some epithelial original tumours (Geahlen 2014); however, it has also been hypothesised to have a tumour suppressor role in cancers of non-immune cells (Moroni et al. 2004; Coopman et al. 2000; Coopman and Mueller 2006; Krisenko and Geahlen 2015). A decrease in Syk expression in highly malignant and invasive tumour cells has been observed in a range of cancers including lung (Chuanliang et al. 2016) and hepatocellular cancer (Hong et al. 2012; Yuan et al. 2006). Expression has been found negatively associated with cell proliferation and anchorage-independent growth; moreover, negative associations have also been detected between Syk and cell migration, lymphovascular invasion, microvessel density and/or metastasis formation in cancers (Ogane et al. 2009; Fei et al. 2013; Nakashima et al. 2006; Coopman and Mueller 2006; Peng et al. 2013; Chuanliang et al. 2016).

Data in the literature have suggested potential interactions between Syk and the calpain system. A C-terminal fragment (40-45 kDa) of Syk was generated by calpain cleavage of human recombinant Syk (Baldock et al. 2000) and calpain inhibitors have been shown to significantly increase the presence of full-length Syk $(72 \mathrm{kDa})$ on cell membrane (Gonscherowski et al. 2006) suggesting that Syk is a calpain substrate. An additional study suggests that Syk appears upstream of calpains rather than being a calpain substrate thus the effect of Syk on calpain activity seems contradictory and may depend on the cellular context (Fei et al. 2013).

A recent study suggested an association between Syk and MAP4 in ovarian cancer cells (Yu et al. 2015). MAP4 is the predominant human non-tubulin component of microtubule-associated protein in non-neuronal tissues (Orr et al. 2003). Syk-mediated tyrosine phosphorylation of MAP1B and MAP4 can induce paclitaxel resistance via reducing microtubule stabilisation (Yu et al. 2015; Krisenko et al. 2014; Wei and Birrer 2015).

As mentioned above, results from previous ovarian cancer studies confirm that the calpain system is associated with patient overall survival, particularly calpain- 2 expression. In addition, calpain-1 expression showed significant association with tumour stage suggesting that calpain-1 might mediate tumour spread (Zhang et al. 2018). The current study sought to assess Syk and MAP4 expression in a large cohort of ovarian cancer specimens, to evaluate associations with patient clinical outcomes and other clinicopathological factors and additionally sought to determine whether there were any correlations between the expression of Syk, MAP4 and the calpain system.

\section{Materials and methods}

\section{Clinical samples}

The ovarian tissue microarray was composed of tumour cores from 575 ovarian cancer cases, with 448 chemo-naïve

Table 1 Clinicopathologic variables of the patient cohort

\begin{tabular}{|c|c|c|}
\hline Variable & $\begin{array}{l}\text { Number of } \\
\text { patients }\end{array}$ & Percentage $(\%)$ \\
\hline \multicolumn{3}{|l|}{ Age } \\
\hline$\leq 62$ & 295 & 52.4 \\
\hline$>62$ & 268 & 47.6 \\
\hline \multicolumn{3}{|l|}{ Histological subtypes } \\
\hline HGSC & 337 & 59.7 \\
\hline Mucinous carcinoma & 60 & 10.6 \\
\hline Endometrioid carcinoma & 68 & 12.1 \\
\hline $\mathrm{CCC}$ & 53 & 9.4 \\
\hline LGSC & 30 & 5.3 \\
\hline SBOT & 15 & 2.7 \\
\hline \multicolumn{3}{|l|}{ Grade } \\
\hline 1 & 48 & 8.5 \\
\hline 2 & 90 & 16.0 \\
\hline 3 & 425 & 75.5 \\
\hline \multicolumn{3}{|l|}{ Stage } \\
\hline I & 203 & 36.7 \\
\hline II & 64 & 11.6 \\
\hline III & 245 & 44.3 \\
\hline IV & 41 & 7.4 \\
\hline \multicolumn{3}{|l|}{ Residual disease } \\
\hline No residual tumour & 311 & 62.2 \\
\hline Residual tumour $(<2 \mathrm{~cm})$ & 58 & 11.6 \\
\hline Residual tumour $(>2 \mathrm{~cm})$ & 131 & 26.2 \\
\hline \multicolumn{3}{|l|}{ Adjuvant therapy } \\
\hline Pt-based chemotherapy & 357 & 63.3 \\
\hline Non-platinum-based chemotherapy & 6 & 1.1 \\
\hline No chemotherapy & 80 & 14.2 \\
\hline Information not available & 121 & 21.5 \\
\hline \multicolumn{3}{|l|}{ Response to chemotherapy } \\
\hline Refractory and resistance & 66 & 17.7 \\
\hline Sensitivity & 307 & 82.3 \\
\hline \multicolumn{3}{|l|}{ Progression status } \\
\hline No recurrence & 137 & 32.9 \\
\hline Recurred & 280 & 67.1 \\
\hline \multicolumn{3}{|l|}{ Survival status } \\
\hline Living & 234 & 42.0 \\
\hline Deceased & 323 & 58.0 \\
\hline
\end{tabular}


samples, as described previously (Zhang et al. 2018). The clinicopathological variables of the cohort are listed in Table 1. Patients were diagnosed with ovarian cancer and received treatment at Nottingham University Hospitals between 1991 and 2011. The majority of the patients $(n=357)$ received platinum-based chemotherapy among which 168 patients were treated with chemotherapy containing taxanes. Progression-free survival was defined as the length of time between start of treatment and clinical identification of recurrence. Data on resistance to chemotherapy was recorded, classified by the Gynaecologic Oncology Group (GOG) as either refractory (not responding to chemotherapy), resistant (an initial response to chemotherapy with recurrence within 6 months) or sensitive (when there was either no recurrence or recurred after 6 months). Ethical approval was obtained from Derbyshire Ethics Committee (07/H0401/156). This study is reported in accordance with REMARK (reporting recommendations for tumour marker prognostic studies) criteria (McShane et al. 2005).

\section{Tissue microarray, immunohistochemistry and interpretation}

Protein expression was investigated using sections taken from the same tissue microarray blocks that were used in the previous study, that assessed calpain system protein expression, i.e., calpain-1, -2, -4 and calpastatin (Zhang et al. 2018). For the majority of the cases, a single tissue core was used for each patient. Fresh sections $(4 \mu \mathrm{m})$ were cut from each block and placed on coated glass slides for the immunohistochemical assessment of protein expression.

Immunohistochemistry was performed as described previously (Storr et al. 2012; Zhang et al. 2018). Primary antibodies were diluted in Bond Primary Antibody Diluent (Leica, Denmark), MAP4 antibody (1:400; Bethyl Laboratories, INC; A301-489A) and Mouse monoclonal anti-human Syk antibody (4D10.1) (1:1600; Thermo Fisher Scientific; MA5-13087), and applied to the tissue overnight at $4{ }^{\circ} \mathrm{C}$. The specificity of these antibodies was initially confirmed by Western blotting before conducting IHC (Fig. S1). Negative controls omitted primary antibody. Slides were scanned and cytoplasmic staining intensity semi-quantitatively assessed, for Syk and MAP4, using an immunohistochemical H-score as described previously (Storr et al. 2012; Zhang et al. 2018). Nuclear staining intensity was also scored for Syk, and the percentage of stained nuclei recorded. Greater than $25 \%$ of the slides were examined by a second independent assessor blinded to scores and clinicopathologic criteria. Single measure intraclass correlation coefficient (ICC) analysis was used to determine the level of agreement between independent scorers. The single measure ICCs between scores were $0.925,0.833$ and 0.887 for anti-Syk antibody cytoplasmic and nuclear-stained samples, and anti-MAP4 antibodystained samples, respectively. A non-biased cut-point of the immunohistochemical scores, to dichotomise data, was determined using X-tile software using patient OS (Camp et al. 2004; Storr et al. 2012).

\section{Statistical analysis}

The relationships between categorised protein expression and clinicopathologic factors were examined using Pearson's Chi-squared test of association $\left(\chi^{2}\right)$ or Fisher's exact test if a cell count was less than 5 in a $2 \times 2$ table. To assess the relationship between protein expression and survival outcomes, survival curves were generated using the Kaplan-Meier method and statistical significance determined by the Logrank test. Multivariate survival analysis was performed using a proportional hazards model by Cox regression analysis to estimate hazard ratios and $95 \%$ confidence intervals for overall survival. Spearman's rank correlation coefficient (Spearman's $\rho$ ) test was performed to assess the correlation between the expression levels of different proteins. The correlation strength was interpreted as follows: Spearman $\rho$ (rs) less than 0.16 is too weak to be meaningful, ranging from 0.16 to 0.19 as very weak correlation; 0.20 to 0.39 as a weak correlation; 0.40 to 0.59 as a moderate correlation; 0.60 to 0.79 as strong correlation and 0.80 or greater as very strong correlation (Divaris et al. 2012). Statistical analyses were carried out using SPSS 22.0 software. $P$ values $<0.05$ were considered statistically significant.

\section{Results}

Similar to reports by Zhang et al. (2009) and Fei et al. (2013) Syk was expressed in both the cytosol and nucleus. MAP4 showed predominant staining in the cytoplasm of the ovarian cancer cells with membranous staining apparent. Representative staining patterns of weak, moderate, and strong staining intensity are shown in Fig. 1. Both Syk and MAP4 showed granular/diffuse staining with heterogeneity between adjacent cancer cells. In addition to the staining of tumour cells, Syk and MAP4 staining was observed in areas of tumour-adjacent normal tissue; moreover, Syk staining was also observed in immune cells. The current study focused only on the staining of tumour cells.

\section{The expression of Syk and MAP4 and clinicopathological factors}

High cytoplasmic Syk (Syk-c) expression was observed in 374 (85\%) out of 441 cases, and nuclear Syk (Syk-n) expression was observed in 329 (75\%) cases (Syk-c cut-point: 65; Syk-n cut-point: 12). Pearson's Chi-squared test was 
Fig. 1 Representative photomicrographs of Syk and MAP4 expression in ovarian carcinoma cells. Expression levels, including low (left), medium (middle) and high (right) staining, of Syk and MAP4 at $\times 10$ magnification with $\times 20$ magnification inset panel. Negative controls omitted primary antibody. Scale bar represents $100 \mu \mathrm{m}$

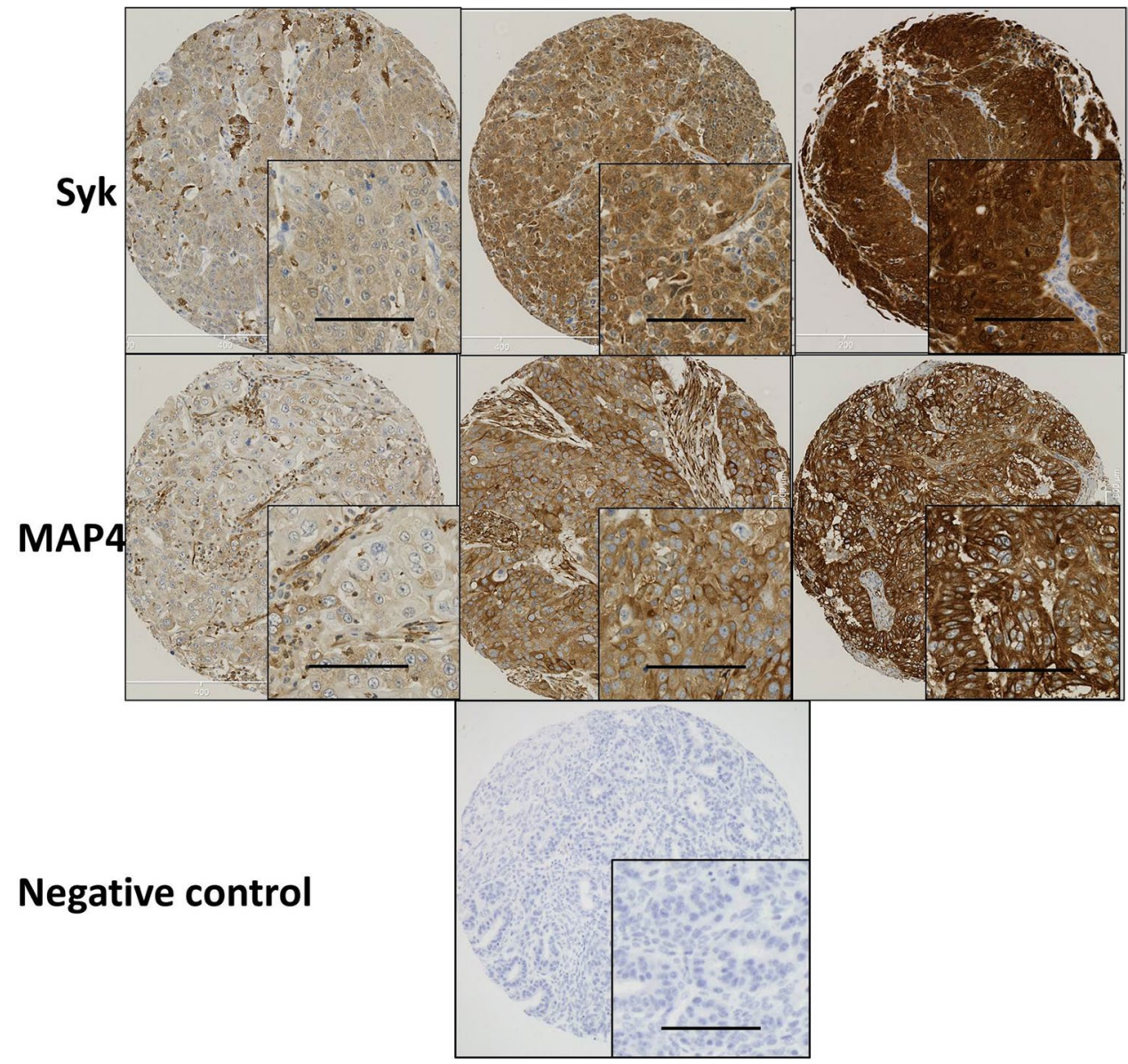

performed to evaluate the relationships with the expression of calpain-system proteins and with clinicopathologic characteristics, with results shown in Table 2. HGSCs often displayed higher Syk expression in the cytoplasm and nucleus (Syk-c: $\chi^{2}=58.835, d f=5, P=2.115 \mathrm{E}-11$ and Syk-n: $\chi^{2}=29.874, d f=5, P=0.000016$, respectively). Low Syk-c expression was linked with lower stage $\left(\chi^{2}=10.725, d f=3\right.$, $P=0.013$ ), whilst low Syk-n expression significantly associated with chemo-resistance in patient treated by therapy containing taxanes $\left(\chi^{2}=7.582, d f=1, P=0.006\right)$.

The above analysis was also conducted in chemotherapynaïve cases $(n=448)$ (data not shown). Significant associations were found between Syk expression and ovarian cancer subtype (Syk-c: $\chi^{2}=46.443, d f=5, P=7.3773 \mathrm{E}-9$; Syk-n: $\chi^{2}=26.744, d f=5, P=0.000064$ ), stage (only Sykc: $\left.\chi^{2}=11.520, d f=3, P=0.009\right)$, and tumour response to taxane-containing chemotherapy (only Syk-n: $\chi^{2}=7.078$, $d f=1, P=0.008)$.

High MAP4 expression was observed in 291 (66\%) out of 442 cases (cut-point: 152). Pearson's Chi-squared test was performed to evaluate the associations of clinicopathological factors with MAP4 expression (Table 3). HGSCs exhibited significantly higher MAP4 expression $\left(\chi^{2}=56.386\right.$, $d f=5, P=6.7681 \mathrm{E}-11)$. Low expression was significantly associated with lower stage $\left(\chi^{2}=15.857, d f=3, P=0.001\right)$ and lower grade $\left(\chi^{2}=22.933, d f=2, P=0.00001\right)$. A significant association was detected between high MAP4 expression and the presence of residual tumour $\left(\chi^{2}=10.426, d f=2\right.$, $P=0.005)$.

The above analysis was also conducted in chemotherapy-naïve cases $(n=448)$. MAP4 expression was significantly associated with subtype $\left(\chi^{2}=45.528, d f=5\right.$, $P=1.1332 \mathrm{E}-8)$, grade $\left(\chi^{2}=14.209, d f=2, P=0.001\right)$, stage $\left(\chi^{2}=15.050, d f=3, P=0.002\right)$, residual disease $\left(\chi^{2}=9.965\right.$, $d f=1, P=0.007)$ and tumour response to taxane-containing chemotherapy $\left(\chi^{2}=4.596, d f=1, P=0.032\right.$; high MAP4 expression associated with chemo-sensitisation).

Patients were then grouped according to whether they had an organ-confined tumour (i.e., group 1: stage 1 and group 2: stage 2-4) or according to whether they had distant metastasis (i.e., group 1: stage 1-3 and group 2: stage 4). Higher significance was observed for Syk and MAP4 expression, regarding tumour spread, when grouping patients into two broader categories by organ-confined status than grouping by FIGO staging classifications (Table S1). Low Syk-c, low Syk-n and low MAP4 showed significant association with organ-confined status of tumour (Syk-c: $\chi^{2}=9.975, d f=1$, $P=0.002$; Syk-n: $\chi^{2}=4.169, d f=1, P=0.041$; and MAP4: 
Table 2 Association between Syk expression and clinicopathological criteria

\begin{tabular}{|c|c|c|c|c|c|c|c|c|c|}
\hline \multirow[t]{2}{*}{ Variable } & \multicolumn{4}{|c|}{ Syk-c expression } & \multicolumn{5}{|c|}{ Syk-n expression } \\
\hline & Low & High & & $P$ value & Low & & High & & $P$ value \\
\hline \multicolumn{10}{|l|}{ Age } \\
\hline$\leq 62$ & $30(6.8 \%)$ & $184(41.8 \%)$ & 0.492 & & $51(11.6 \%)$ & & & $163(37.0 \%)$ & 0.447 \\
\hline$>62$ & $37(8.4 \%)$ & $189(43.0 \%)$ & & & $61(13.9 \%)$ & & & $65(37.5 \%)$ & \\
\hline \multicolumn{10}{|l|}{ Histological subtypes } \\
\hline HGSC & $25(5.7 \%)$ & $247(56.0 \%)$ & $2.115 \mathrm{E}-11 *$ & & $57(12.9 \%)$ & & $215(48.8 \%)$ & & $1.6 \mathrm{E}-5^{*}$ \\
\hline Mucinous & $9(2.0 \%)$ & $34(7.7 \%)$ & & & $10(2.3 \%)$ & & $33(7.5 \%)$ & & \\
\hline Endometrioid & $9(2.0 \%)$ & $45(10.2 \%)$ & & & $16(3.6 \%)$ & & $38(8.6 \%)$ & & \\
\hline $\mathrm{CCC}$ & $23(5.2 \%)$ & $21(4.8 \%)$ & & & $25(5.7 \%)$ & & $19(4.3 \%)$ & & \\
\hline LGSC & $1(0.2 \%)$ & $17(3.9 \%)$ & & & $4(0.9 \%)$ & & $14(3.2 \%)$ & & \\
\hline SBOT & $0(0.0 \%)$ & $10(2.3 \%)$ & & & $0(0.0 \%)$ & & $10(2.3 \%)$ & & \\
\hline \multicolumn{10}{|l|}{ Grade } \\
\hline 1 & $4(0.9 \%)$ & $29(6.6 \%)$ & 0.813 & & $7(1.6 \%)$ & & $26(5.9 \%)$ & & 0.174 \\
\hline 2 & $9(2.0 \%)$ & $56(12.7 \%)$ & & & $11(2.5 \%)$ & & $54(12.2 \%)$ & & \\
\hline 3 & $54(12.2 \%)$ & $289(65.5 \%)$ & & & $94(21.3 \%)$ & & $249(56.5 \%)$ & & \\
\hline \multicolumn{10}{|l|}{ Stage } \\
\hline I & $36(8.3 \%)$ & $123(28.3 \%)$ & $\mathbf{0 . 0 1 3}^{*}$ & & $50(11.5 \%)$ & & $109(25.1 \%)$ & & 0.209 \\
\hline II & $6(1.4 \%)$ & $43(9.9 \%)$ & & & $12(2.8 \%)$ & & $37(8.5 \%)$ & & \\
\hline III & $20(4.6 \%)$ & $175(40.3 \%)$ & & & $42(9.7 \%)$ & & $153(35.3 \%)$ & & \\
\hline IV & $5(1.2 \%)$ & $26(6.0 \%)$ & & & $8(1.8 \%)$ & & $23(5.3 \%)$ & & \\
\hline \multicolumn{10}{|l|}{ Residual disease } \\
\hline No residual tumour & $44(11.3 \%)$ & $195(50.0 \%)$ & 0.227 & & $72(18.5 \%)$ & & $167(42.8 \%)$ & & 0.076 \\
\hline Residual tumour $(<2 \mathrm{~cm})$ & $5(1.3 \%)$ & $41(10.5 \%)$ & & & $10(2.6 \%)$ & & $36(9.2 \%)$ & & \\
\hline Residual tumour $(>2 \mathrm{~cm})$ & $13(3.3 \%)$ & $92(23.6 \%)$ & & & $20(5.1 \%)$ & & $85(21.8 \%)$ & & \\
\hline \multicolumn{10}{|c|}{ Response to platinum-based chemotherapy } \\
\hline Chemo-refractory & $6(2.1 \%)$ & $24(8.5 \%)$ & $0.589^{*}$ & & $13(4.6 \%)$ & $17(6.0 \%)$ & & & 0.154 \\
\hline Chemo-resistance & $2(0.7 \%)$ & $19(6.7 \%)$ & & & $6(2.1 \%)$ & $15(5.3 \%)$ & & & \\
\hline Chemo-sensitivity & $35(12.4 \%)$ & $196(69.5 \%)$ & & & $61(21.6 \%)$ & $170(60.3 \%)$ & & & \\
\hline \multicolumn{10}{|c|}{ Response to taxane-containing (i.e., paclitaxel, docetaxel) chemotherapy regimens } \\
\hline Chemo-resistance & $3(2.5 \%)$ & $18(14.8 \%)$ & $0.774 *$ & & $11(9.0 \%)$ & $10(8.2 \%)$ & & & 0.006 \\
\hline Chemo-sensitivity & $17(13.9 \%)$ & $84(68.9 \%)$ & & & $23(18.9 \%)$ & $78(63.9 \%)$ & & & \\
\hline
\end{tabular}

HGSC high-grade serous carcinoma, LGSC low-grade serous carcinoma, CCC clear-cell carcinoma, SBOT serous borderline ovarian tumour *Expected count less than 5. Significant $P$ values are indicated by bold font

$\left.\chi^{2}=15.402, d f=1, P=0.000087\right)$, whereas no significant association was detected between protein expression and cancer distant metastasis. In chemotherapy-naïve cases $(n=448)$, low Syk-c, low Syk-n and low MAP4 also showed significant association with organ-confined status of tumour (Syk-c: $\chi^{2}=10.551, d f=1, P=0.001$; Syk-n: $\chi^{2}=5.041$, $d f=1, P=0.025$; MAP4: $\chi^{2}=14.322, d f=1, P=0.000154$ ). Such findings suggest that, similar to previous observations with calpain-1, MAP4 and Syk expression may be more related to early events of tumour spread.

\section{The expression of Syk and MAP4 and clinical outcomes}

The expression of Syk-c, -n or MAP4 had no significant associations with overall survival (Fig. 2a, c and e) or progression-free survival (Fig. 2b, d and f). Further analysis was conducted to investigate the prognostic significance of Syk and MAP4 in the individual subgroups defined by clinicopathologic variables. $P$ values of log-rank tests for overall survival in association with each protein expression are listed in Table S2. High Syk-n expression indicated a better overall survival among platinum-resistant patients ( $P=0.001$, Fig. $3 \mathrm{a})$, patients with tumours confined to the ovaries (stage 1 ovarian cancer) $(P=0.001$, Fig. $3 b)$ and patients with no residual disease $(P=0.001)$ (Fig. 3c). 
Table 3 Association between MAP4 expression and clinicopathological criteria

\begin{tabular}{lccl}
\hline Variable & MAP4 & & \\
\cline { 2 - 4 } & Low & High & $P$ value \\
\hline Age & & & \\
$\leq 62$ & $82(18.6 \%)$ & $136(30.8 \%)$ & 0.169 \\
$>62$ & $70(15.9 \%)$ & $153(34.7 \%)$ & \\
Histological subtypes & & & \\
HGSC & $59(13.3 \%)$ & $211(47.7 \%)$ & $\mathbf{6 . 7 6 8 1 E}-\mathbf{1 1}$ \\
Mucinous & $25(5.7 \%)$ & $16(3.6 \%)$ & \\
Endometrioid & $22(5.0 \%)$ & $33(7.5 \%)$ & \\
CCC & $29(6.6 \%)$ & $16(3.6 \%)$ & \\
LGSC & $11(2.5 \%)$ & $8(1.8 \%)$ & \\
SBOT & $6(1.4 \%)$ & $6(1.4 \%)$ & \\
Grade & & & \\
1 & $16(3.6 \%)$ & $19(4.3 \%)$ & $\mathbf{0 . 0 0 0 0 1}$ \\
2 & $38(8.6 \%)$ & $28(6.3 \%)$ & \\
3 & $97(22.0 \%)$ & $243(55.1 \%)$ & \\
Stage & & & \\
I & & & \\
II & $75(17.2 \%)$ & $89(20.5 \%)$ & $\mathbf{0 . 0 0 1}$ \\
III & $12(2.8 \%)$ & $36(8.3 \%)$ & \\
IV & $52(12.0 \%)$ & $140(32.2 \%)$ & \\
Residual disease & $10(2.3 \%)$ & $21(4.8 \%)$ & \\
No residual tumour & $97(24.8 \%)$ & $144(36.8 \%)$ & $\mathbf{0 . 0 0 5}$ \\
Residual tumour (<2 cm) & $10(2.6 \%)$ & $38(9.7 \%)$ & \\
Residual tumour $>2$ cm) & $27(6.9 \%)$ & $75(19.2 \%)$ & \\
Response to platinum-based chemotherapy & & \\
Chemo-refractory & $8(2.8 \%)$ & $22(7.8 \%)$ & 0.509 \\
Chemo-resistance & $8(2.8 \%)$ & $11(3.9 \%)$ & \\
Chemo-sensitivity & $725.5 \%)$ & $161(57.1 \%)$ & \\
Response to taxane-containing (i.e., paclitaxel, docetaxel) chemo- & & \\
therapy regimens & & & \\
Chemo-resistance & & & \\
Chemo-sensitive & & & \\
\hline
\end{tabular}

$H G S C$ high-grade serous carcinoma, LGSC low-grade serous carcinoma, $C C C$ clear-cell carcinoma, $S B O T$ serous borderline ovarian tumour

*Expected count less than 5. Significant $P$ values are indicated by bold type

\section{Correlations between calpain family expression and calpain-associated protein expression}

Correlations between Syk and MAP-4 expression with calpain system proteins (i.e., calpain-1, $-2,-4$ and calpastatin) were studied in the whole cohort. The correlation strength between calpain-2 expression and Syk and MAP4 expression are considered too weak to be meaningful $(\mathrm{rs}<0.16)$. Nevertheless, MAP4 expression was moderately correlated with calpain-1 ( $\mathrm{rs}=0.537, P<0.001)$ (Table 4$)$; in addition,
Syk-c and Syk-n expression were strongly associated with each other ( $\mathrm{rs}=0.809, P<0.001)$ (Table 4$)$.

The correlations were also studied in each histological subtype separately (data not shown). The moderate correlation between calpain-1 and MAP4 was also observed in HGSCs ( $\mathrm{rs}=0.472, P<0.001, n=255)$ and CCCs (rs $=0.516, P<0.001, n=42$ ), whilst strong correlation was observed in endometrioid ( $\mathrm{rs}=0.687, P<0.001, n=50$ ) and mucinous tumours ( $\mathrm{rs}=0.708, P<0.001, n=36$ ), with no significant correlation detected between calpain- 1 and MAP4 in LGSC. For calpain-1 and Syk expression, a weak correlation was found in the whole cohort and also in HGSCs (Syk-c: rs $=0.347, P<0.001, n=257$; Syk-n: $r s=0.313$, $P<0.001, n=257$ ) and CCCs (Syk-c: $\mathrm{rs}=0.378, P=0.014$, $n=42$; Syk-n: rs $=0.327, P=0.035, n=42$ ), whilst a moderate correlation was found in mucinous tumours (Syk-c: rs $=0.425, P=0.007, n=39$; Syk-n: rs $=0.471, P=0.002$, $n=39$ ), no correlation was detected between calpain-1 and Syk expression in LGSCs or endometrioid tumours. Either no correlation or weak correlation was detected between Syk-n and MAP4 expression in the whole cohort and in the five groups of histological subtypes (data not shown). Between Syk-c and MAP4 expression, a weak correlation was found in the whole cohort and also in HGSCs (rs $=0.312, P<0.001, n=265$ ) and mucinous tumours ( $\mathrm{rs}=0.376, P=0.018, n=39$ ), whilst a moderate correlation was found in CCCs ( $\mathrm{rs}=0.576, P<0.001, n=44$ ); no correlation was detected between Syk and MAP4 expression in LGSCs or endometrioid tumours (data not shown). It is noticeable that CXCR3 and Syk expression lacked correlation or was weakly correlated in the whole cohort and 4 of the histological subtypes; only in LGSC type, strong correlation was detected (Syk-c: rs $=0.640, P=0.006, n=17$; Syk-n: rs $=0.606, P=0.010, n=17)$. Findings suggest that the role this panel of proteins played and how they cooperated with each other may be histological subtype dependent.

Additional survival analysis was conducted by recategorised tumours according to expression of any two of MAP4, Syk-c, Syk-n, calpain-1, -2, -4 and calpastatin into four groups each time; for example, grouping patients into the following four groups (i.e., high Syk-n and high Syk-c; high Syk-n and low Syk-c; low Syk-n and high Syk-c; low Syk-n and low Syk-c). On the survival analysis, the $P$ values from the log-rank test obtained with recategorised groups were less significant than those obtained with single marker (Table S3).

\section{Discussion}

Among the ovarian cancer histological subtypes, HGSCs displayed higher expression of Syk-c and -n (Syk-c: $\chi^{2}=58.835, d f=5, P=2.115 \mathrm{E}-11$ and Syk-n: $\chi^{2}=29.874$, 

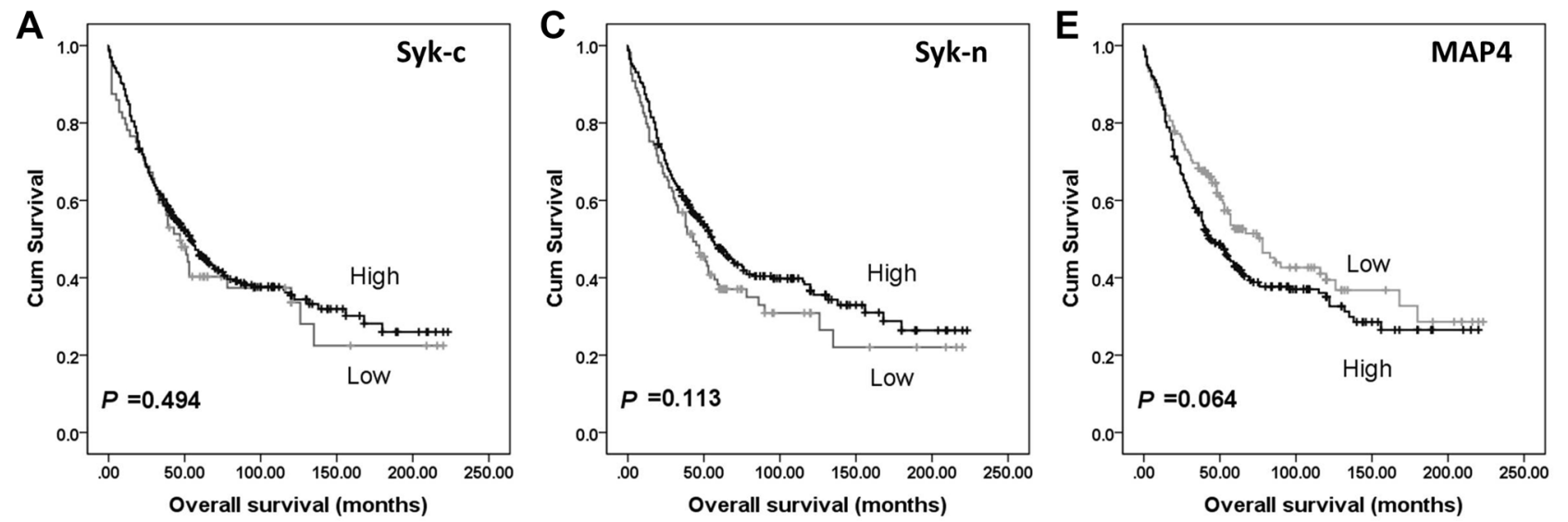

\begin{tabular}{c|cccccc} 
& 0 & 50 & 100 & 150 & 200 & 250 \\
\hline Low expression & 64 & 25 & 11 & 4 & 3 & 0 \\
High expression & 363 & 149 & 64 & 19 & 6 & 0
\end{tabular}

\begin{tabular}{c|cccccc} 
& 0 & 50 & 100 & 150 & 200 & 250 \\
\hline Low expression & 109 & 39 & 12 & 5 & 3 & 0 \\
High expression & 318 & 135 & 63 & 18 & 6 & 0
\end{tabular}

\begin{tabular}{c|cccccc} 
& 0 & 50 & 100 & 150 & 200 & 250 \\
\hline Low expression & 149 & 67 & 30 & 10 & 6 & 0 \\
High expression & 279 & 114 & 49 & 15 & 3 & 0
\end{tabular}
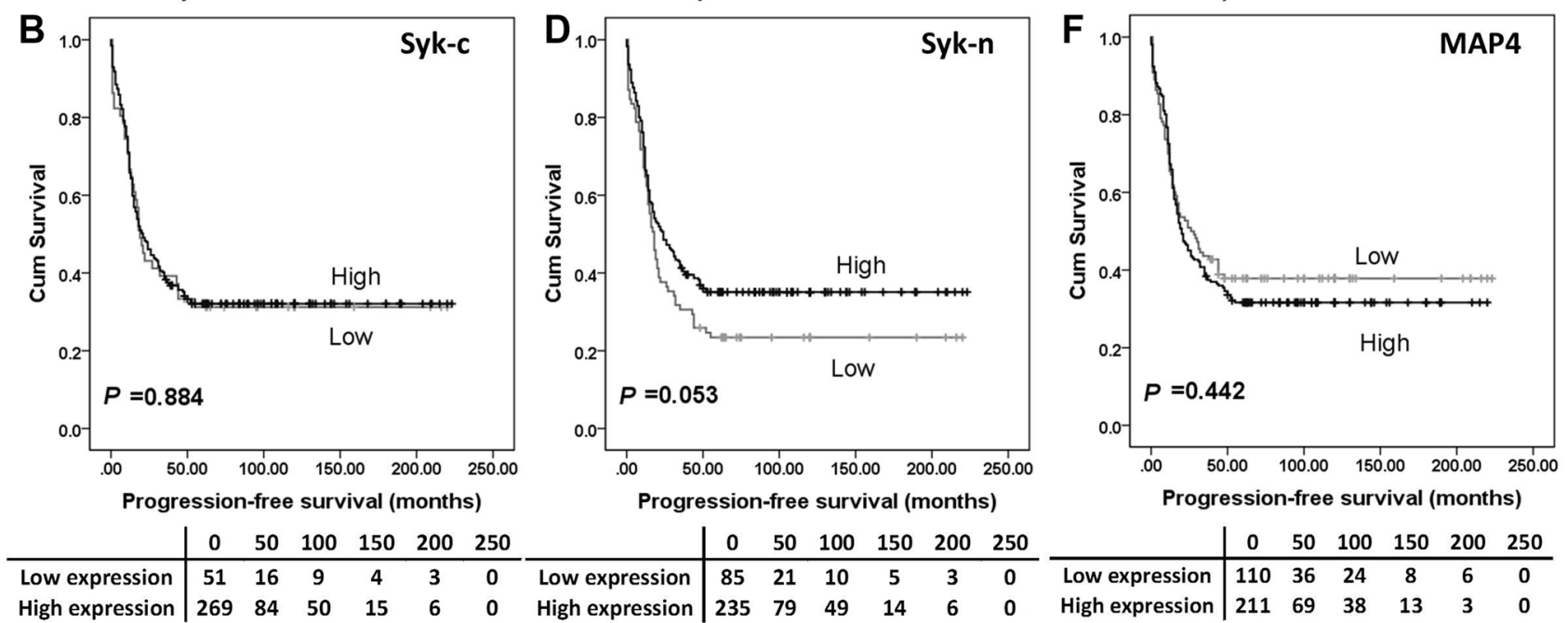

Fig. 2 Kaplan-Meier survival curves show the impact of Syk-c, Syk-n and MAP4 expression on overall survival and progressionfree survival. There were no differences in survival between patients with tumours expressing high MAP4 or Syk and those with tumours

$d f=5, P=0.000016$, respectively). In addition, the present study indicated that low Syk-c expression was associated with lower tumour stage $\left(\chi^{2}=10.725, d f=3, P=0.013\right)$. In light of such data, it is likely that Syk may promote tumour spread via increasing cell invasion and migration at the early stage of ovarian carcinogenesis. Consistently, high Syk expression (mRNA level, $n=45$; protein level, $n=38$ ) significantly correlated with worse survival, enhanced cell migration and metastases to the lymph nodes in patients with squamous cell carcinomas of the head and neck (Luangdilok et al. 2007). Other pro-survival functions of Syk include anti-apoptosis (Geahlen 2014; Krisenko and Geahlen 2015), cancer cell growth and survival (Prinos et al. 2011; Udyavar et al. 2013; Fei et al. 2013), migration and dissemination (Luangdilok et al. 2007; Ghotra et al. 2015; Katz et al. 2005; Krisenko and Geahlen 2015). Yet, other studies suggest that expressing low MAP4 or Syk. Significance was determined using the log-rank test. The tables shown below the Kaplan-Meier survival curves listed the number of patients at risk at the specific months. High expression—black line, low expression—grey line

Syk is absent from many highly aggressive epithelial cellderived tumours (Krisenko and Geahlen 2015; Coopman and Mueller 2006) and Syk may increase cell-cell interactions and limit EMT (Krisenko and Geahlen 2015). To be specific, Syk knockdown in more well-differentiated cancers was found to enhance invasive/anchorage-independent growth and motility (Fei et al. 2013) whilst its re-introduction in more malignant, invasive cancer cells decreased cancer malignancy through increasing adhesion and reducing tumour cell growth, motility, invasion and metastasis (Ogane et al. 2009; Fei et al. 2013; Peng et al. 2013; Krisenko and Geahlen 2015). The invasion suppressive function of fulllength Syk has been reported to correlate with Syk nuclear localisation suggesting that Syk-n possesses biological activities associated with tumour suppression in mammary epithelial cells (Wang et al. 2003). 

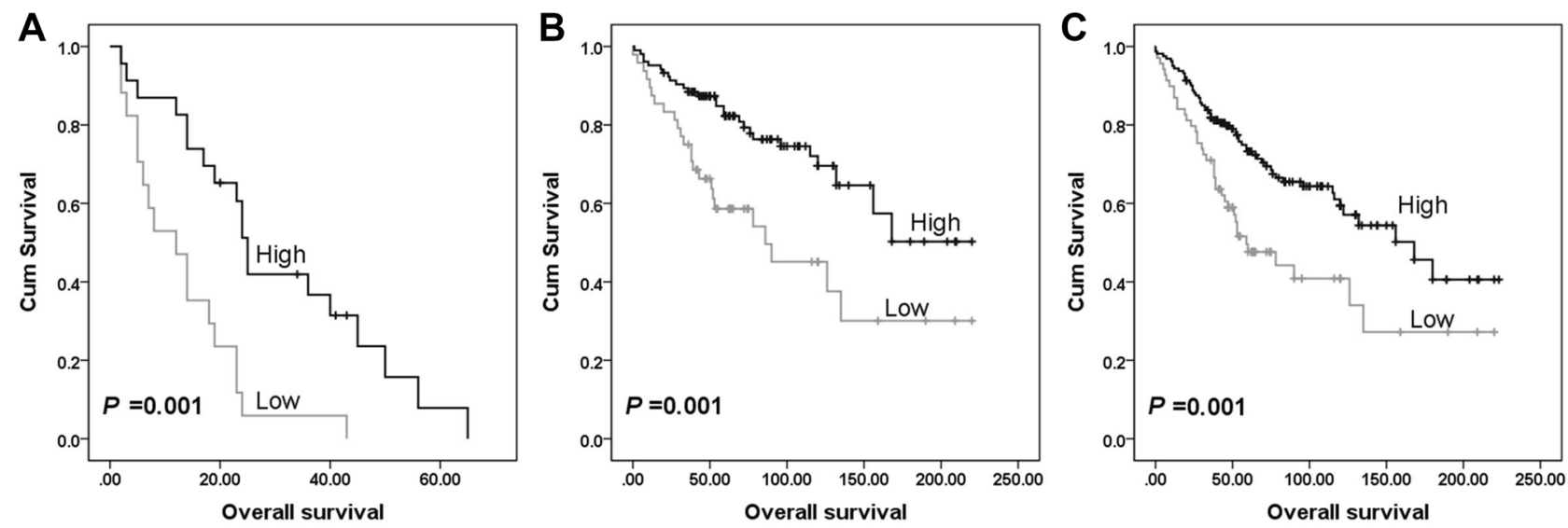

\begin{tabular}{|c|c|c|c|c|c|c|c|c|c|c|c|c|c|c|c|c|c|c|}
\hline & 0 & 20 & 40 & 60 & & 0 & 50 & 100 & 150 & 200 & 250 & & 0 & 50 & 100 & 150 & 200 & 250 \\
\hline Low expression & 17 & 4 & 1 & 0 & Low expression & 48 & 26 & 10 & 4 & 2 & 0 & Low expression & 69 & 32 & 10 & 4 & 2 & 0 \\
\hline High expression & 23 & 14 & 6 & 1 & High expression & 104 & 72 & 38 & 10 & 4 & 0 & High expression & 161 & 99 & 50 & 14 & 5 & 0 \\
\hline
\end{tabular}

Fig. 3 Kaplan-Meier survival curves show the impact of Syk expression on overall survival in different subgroups. Survival analysis shows that high Syk-n expression significantly associated with better $(P=0.010)$ overall survival for ovarian cancer patients resistant to platinum-based chemotherapy (a), patients with tumour confined to the ovaries (b) and patients with no residual carcinoma (c). Significance was determined using the log-rank test. The tables shown below the Kaplan-Meier survival curves listed the number of patients at risk at the specific months. High expression-black line, low expression-grey line

Table 4 Spearman's rank correlation coefficient between defined proteins of interest ( 469 valid cases)

\begin{tabular}{|c|c|c|c|c|}
\hline & Calpastatin & Calpain-1 & Calpain-2 & Calpain-4 \\
\hline \multicolumn{5}{|l|}{ Syk-c } \\
\hline $\mathrm{rs}$ & $0.135^{*}$ & $0.396 *$ & $0.127 *$ & $0.145^{*}$ \\
\hline Sig. & 0.006 & $4.3041 \mathrm{E}-17$ & 0.010 & 0.003 \\
\hline$N$ & 415 & 416 & 415 & 416 \\
\hline \multicolumn{5}{|l|}{ Syk-n } \\
\hline rs & $0.160^{*}$ & $0.346^{*}$ & 0.082 & $0.129 *$ \\
\hline Sig. & 0.001 & $4.0912 \mathrm{E}-13$ & 0.097 & 0.009 \\
\hline$N$ & 415 & 416 & 415 & 416 \\
\hline \multicolumn{5}{|c|}{ MAP4 } \\
\hline rs & $0.244^{*}$ & $0.537 *$ & $0143^{*}$ & $0.286^{*}$ \\
\hline Sig. & $4.8817 \mathrm{E}-7$ & $2.3144 \mathrm{E}-32$ & 0.004 & $2.8108 \mathrm{E}-9$ \\
\hline \multirow[t]{2}{*}{$N$} & 414 & 415 & 414 & 415 \\
\hline & \multicolumn{2}{|r|}{ Syk-c } & \multicolumn{2}{|r|}{ Syk-n } \\
\hline \multicolumn{5}{|c|}{ MAP4 } \\
\hline rs & \multicolumn{2}{|r|}{$0.385^{*}$} & & $0.290 *$ \\
\hline Sig. & & \multicolumn{2}{|l|}{$1.350 \mathrm{E}-16(n=429)$} & $9.765 \mathrm{E}-10(n=429)$ \\
\hline \multicolumn{5}{|l|}{ Syk-c } \\
\hline rs & & \multicolumn{2}{|l|}{-} & $0.809 *$ \\
\hline Sig. & & \multicolumn{2}{|l|}{-} & $3.189 \mathrm{E}-103(n=441)$ \\
\hline
\end{tabular}

*Correlation is significant at the 0.01 level (two-tailed)

Significant $P$ values are indicated by bold font

$r s$ Spearman's correlation coefficient, Syk- $n$ nuclear Syk, Syk-c cytoplasmic Syk 
In the current study, a tumour-suppressive effect of Syk-n was reflected in its negative association with chemoresistance in patients treated by therapy containing taxane $\left(\chi^{2}=7.582, d f=1, P=0.006\right)$ and positive association with overall survival when patients had tumours confined to the ovaries (stage 1 ovarian cancer) $(P=0.001)$, in the subgroup of platinum-resistant patients $(P=0.001)$ and in the group of patients with no residual disease $(P=0.001)$. Current findings are in contrast to those from a previous study conducted in ovarian cancer cells where Syk expression/activity levels positively associated with cell resistance to paclitaxel; moreover, in the same study, pharmacological and genomic Syk inhibitors had a synergistic effect with paclitaxel both in vitro and in vivo especially in cells that were resistant to paclitaxel (Yu et al. 2015). A separate study showed that Syk was preferentially expressed in recurrent HGSCs after chemo-therapeutic treatment in comparison with the primary tumours from the same patients (Jinawath et al. 2010). Moreover, restriction of Syk to the nucleus has been suggested to diminish stress-induced activation of caspase 3 in B cells (Zhou et al. 2006; Mohammad et al. 2016) and tumour cells (Wang et al. 2005).

The discrepancy between the above and the strong and positive correlation between Syk-c and -n expression in the current study ( $r s=0.809, P<0.001$ ) may be due to the different splice variants of Syk and their localisation. Although $\operatorname{Syk}(\mathrm{L})$ and $\operatorname{Syk}(\mathrm{S})$ cannot be discriminated via IHC with the antibody used in the current study, which targets amino acids 313-339, Syk-n and Syk-c were studied separately. Full-length Syk is known as Syk long isoform, $\operatorname{Syk}(\mathrm{L})$, whilst the shorter gene product $\operatorname{Syk}(\mathrm{S})$ omits a stretch of 23 amino acids (AA283-305) in linker B (Grädler et al. 2013; Krisenko and Geahlen 2015). Syk(L) and Syk(S) were found in both nucleus and cytoplasm (Wang et al. 2003; Zhou et al. 2006; Luangdilok et al. 2007) with Syk(L) predominantly presenting in the nucleus and $\operatorname{Syk}(\mathrm{S})$ in cytoplasm in untreated tumour cells (Prinos et al. 2011; Wang et al. 2005). A Syk splicing pattern was linked to ovarian but not breast cancer (Klinck et al. 2008; Venables et al. 2008; Prinos et al. 2011) and SKOV3 cells reportedly preferentially express Syk(L) (Prinos et al. 2011). Further investigation is needed to understand the contradictory functions of Syk in terms of cellular context and tumour microenvironment.

In the current study, a significant association was detected between high MAP4 expression and the presence of residual tumour $\left(\chi^{2}=10.426, d f=2, P=0.005\right)$. Low MAP4 expression was significantly associated with lower stage $\left(\chi^{2}=15.857, d f=3, P=0.001\right)$ which agreed with a study of esophageal squamous cell carcinomas $(n=364)$, where MAP4 expression was linked with tumour stage and lymph node metastasis (Jiang et al. 2016). In addition, the knockdown of MAP4 was found able to markedly inhibit bladder cancer cells invasion (Ou et al. 2014). In addition, in the present study, low MAP4 expression was significantly associated with lower grade $\left(\chi^{2}=22.933, d f=2, P<0.001\right)$ which has also been observed in bladder cancer $(n=34)$ (Ou et al. 2014). Although a higher level of MAP4 mRNA was found in non-small cell lung carcinomas when compared to normal lung tissues (Cucchiarelli et al. 2008) and MAP4 expression was associated with shorter survival of the esophageal squamous cell carcinoma patients $(n=364)$ (Jiang et al. 2016), no significant association was detected in the present study between MAP4 expression and overall survival in either the whole cohort or any of the subgroups tested.

An association between MAP4 and paclitaxel resistance has been observed in different cancer types including ovarian cancer (Poruchynsky et al. 2001; Orr et al. 2003; Aoki et al. 2009). In the chemotherapy-naïve cases of the current study, the correlation between high MAP4 expression and chemo-sensitisation was statistically significant in patients treated by taxane-containing chemotherapy $\left(\chi^{2}=4.596\right.$, $d f=1, P=0.032$ ). As an anti-tumour drug, taxane induces microtubule stabilisation and reduces microtubule dynamics which promotes mitotic arrest and cell death (Aoki et al. 2009). Based on the mechanism of taxane on tumour cells, proteins that are involved in the regulation of cellular microtubule dynamics via interacting with tubulin dimers or polymerised microtubules clearly possess the potential for modulating the cell sensitivity towards paclitaxel (Orr et al. 2003). The drug sensitivity profile of ovarian cancer paclitaxel-resistant sublines parallels the regulation of MAP4 modification: MAP4 phosphorylation and dissociation from microtubules decrease the sensitivity of paclitaxel-resistant ovarian cell lines towards paclitaxel (Poruchynsky et al. 2001; Orr et al. 2003). However, down-regulation of MAP4 in SKOV3 cells did not influence the sensitivity to either paclitaxel or cisplatin; and MAP4 status was not correlated with the survival of patients treated with either taxane-based regimen or taxane-free regimen (Aoki et al. 2009). The precise role for MAP4 in tumour sensitivity to taxanes remains to be defined.

As indicated above, results from previous ovarian cancer studies confirm that calpain-2 is an important factor in cancer survival (Storr et al. 2012; Zhang et al. 2018). In addition, calpain- 4 and calpastatin were also associated with patient overall survival (Zhang et al. 2018). Such previous studies focused on protein expression and thus cannot directly reflect the actual enzyme activity level of the calpain system. How the calpain system is involved in patient outcomes remains unclear. With low calpain-1 expression associating with stage 1 tumour (Zhang et al. 2018), in the current study, low Syk-c and MAP4 expression also related to organ-confined status (Syk-c: $\chi^{2}=9.975, d f=1$, $P=0.002$; and MAP4: $\chi^{2}=15.402, d f=1, P=0.000087$ ) (Tables 2, 3). Thus, the calpain system, together with Syk-c 
and MAP4, might be linked with overall survival via their associations with tumour spread. Currently, there is a lack of supporting information to explain the positive correlations between calpain-1 and Syk/MAP4 (MAP4 and calpain-1: rs $=0.537, P=2.3144 \mathrm{E}-32$; Syk-c and calpain-1: rs $=0.396, P=4.3041 \mathrm{E}-17$; MAP4 and Syk-c: $\mathrm{rs}=0.385$, $P=1.350$ E -16 ) (Table 4$)$. In vitro studies focusing on the activity of these proteins and ovarian cancer cell invasion might shed more light on whether, and how, the calpain system interacts with Syk/MAP4 to influence patient outcome.

In conclusion, both MAP4 and Syk were associated with tumour stage. The current study also observed the paradoxical roles of Syk. High Syk-n expression indicated a better overall survival in certain subgroups of patients. Low Syk-n expression significantly associated with chemo-resistance in patients treated by therapy containing taxane which support the role of Syk as a tumour suppressor. Contradictory, low Syk-c expression was associated with low stage. Together, it appears from this study of ovarian cancers that high Syk expression may facilitate tumour spreading (higher stage) whilst high Syk-n sensitises tumour cells to taxane-containing chemotherapy. Significant correlations between MAP4, Syk, and calpain-1 suggest that calpain, Syk and MAP4 might be interrelated and interact on each other to modulate cancer cell spread. How MAP4, Syk and calpain-1 are involved in tumour cell spreading/migration, and in cellular response to taxane-containing chemotherapy, remains to be elucidated.

\section{Compliance with ethical standards}

Conflict of interest The authors declare no conflict of interest.

Ethical standards Permission to use the archived tissue was obtained from Derbyshire Ethics Committee (07/H0401/156)

OpenAccess This article is distributed under the terms of the Creative Commons Attribution 4.0 International License (http://creativeco mmons.org/licenses/by/4.0/), which permits unrestricted use, distribution, and reproduction in any medium, provided you give appropriate credit to the original author(s) and the source, provide a link to the Creative Commons license, and indicate if changes were made.

\section{References}

Aoki D, Oda Y, Hattori S, Taguchi K, Ohishi Y, Basaki Y, Oie S, Suzuki N, Kono S, Tsuneyoshi M et al (2009) Overexpression of class III beta-tubulin predicts good response to taxane-based chemotherapy in ovarian clear cell adenocarcinoma. Clin Cancer Res 15(4):1473-1480. https://doi.org/10.1158/1078-0432. CCR-08-1274

Baldock D, Graham B, Akhlaq M, Graff P, Jones CE, Menear K (2000) Purification and characterization of human Syk produced using a baculovirus expression system. Protein Expr Purif 18(1):86-94
Camp RL, Dolled-Filhart M, Rimm DL (2004) X-tile: a new bioinformatics tool for biomarker assessment and outcome-based cut-point optimization. Clin Cancer Res 10(21):7252-7259

Chuanliang P, Yunpeng Z, Yingtao H, Qifeng S, Xiaogang Z, Bo C (2016) Syk expression in non-small-cell lung cancer and its relation with angiogenesis. J Cancer Res Ther 12(2):663-666. https ://doi.org/10.4103/0973-1482.154082

Coopman PJ, Mueller SC (2006) The Syk tyrosine kinase: a new negative regulator in tumor growth and progression. Cancer Lett 241(2):159-173 (Epub 2006 Jan 27)

Coopman PJ, Do MT, Barth M, Bowden ET, Hayes AJ, Basyuk E, Blancato JK, Vezza PR, McLeskey SW, Mangeat PH, Mueller SC (2000) The Syk tyrosine kinase suppresses malignant growth of human breast cancer cells. Nature 406(6797):742-747

Cucchiarelli V, Hiser L, Smith H, Frankfurter A, Spano A, Correia JJ, Lobert S (2008) Beta-tubulin isotype classes II and V expression patterns in nonsmall cell lung carcinomas. Cell Motil Cytoskelet 65(8):675-685. https://doi.org/10.1002/cm.20297

Divaris K, Vann WF Jr, Baker AD, Lee JY (2012) Examining the accuracy of caregivers' assessments of young children's oral health status. J Am Dent Assoc 143(11):1237-1247

Fei B, Yu S, Geahlen RL (2013) Modulation by Syk of Bcl-2, calcium and the calpain-calpastatin proteolytic system in human breast cancer cells. Biochim Biophys Acta 1833(10):2153-2164. https ://doi.org/10.1016/j.bbamcr.2013.05.010

Geahlen RL (2014) Getting Syk: spleen tyrosine kinase as a therapeutic target. Trends Pharmacol Sci 35(8):414-422. https://doi. org/10.1016/j.tips.2014.05.007

Ghotra VP, He S, van der Horst G, Nijhoff S, de Bont H, Lekkerkerker A, Janssen R, Jenster G, van Leenders GJ, Hoogland AM et al (2015) Syk is a candidate kinase target for the treatment of advanced prostate cancer. Cancer Res 75(1):230-240. https://doi. org/10.1158/0008-5472.CAN-14-0629

Gonscherowski V, Becker BF, Moroder L, Motrescu E, Gil-Parrado S, Gloe T, Keller M, Zahler S (2006) Calpains: a physiological regulator of the endothelial barrier? Am J Physiol Heart Circ Physiol 290(5):H2035-H2042

Grädler U, Schwarz D, Dresing V, Musil D, Bomke J, Frech M, Greiner H, Jäkel S, Rysiok T, Müller-Pompalla D, Wegener A (2013) Structural and biophysical characterization of the Syk activation switch. J Mol Biol 425(2):309-333. https://doi.org/10.1016/j. jmb.2012.11.007

Hong J, Hu K, Yuan Y, Sang Y, Bu Q, Chen G, Yang L, Li B, Huang P, Chen D, Liang Y, Zhang R, Pan J, Zeng YX, Kang T (2012) CHK1 targets spleen tyrosine kinase (L) for proteolysis in hepatocellular carcinoma. J Clin Investig 122(6):2165-2175. https:// doi.org/10.1172/JCI61380

Jiang YY, Shang L, Shi ZZ, Zhang TT, Ma S, Lu CC, Zhang Y, Hao JJ, Shi C, Shi F et al (2016) Microtubule-associated protein 4 is an important regulator of cell invasion/migration and a potential therapeutic target in esophageal squamous cell carcinoma. Oncogene 35(37):4846-4856. https://doi.org/10.1038/onc.2016.17

Jinawath N, Vasoontara C, Jinawath A, Fang X, Zhao K, Yap KL, Guo T, Lee CS, Wang W, Balgley BM et al (2010) Oncoproteomic analysis reveals co-upregulation of RELA and STAT5 in carboplatin resistant ovarian carcinoma. PLoS One 5(6):e11198. https ://doi.org/10.1371/journal.pone.0011198

Katz E, Lareef MH, Rassa JC, Grande SM, King LB, Russo J, Ross SR, Monroe JG (2005) MMTV Env encodes an ITAM responsible for transformation of mammary epithelial cells in three-dimensional culture. J Exp Med 201(3):431-439

Klinck R, Bramard A, Inkel L, Dufresne-Martin G, Gervais-Bird J, Madden R, Paquet ER, Koh C, Venables JP, Prinos P et al (2008) Multiple alternative splicing markers for ovarian cancer. Cancer Res 68(3):657-663. https://doi.org/10.1158/0008-5472. CAN-07-2580 
Krisenko MO, Geahlen RL (2015) Calling in Syk: Syk's dual role as a tumor promoter and tumor suppressor in cancer. Biochim Biophys Acta 1853(1):254-263. https://doi.org/10.1016/j.bbamc r.2014.10.022

Krisenko MO, Cartagena A, Raman A, Geahlen RL (2014) Nanomechanical property maps of breast cancer cells as determined by multiharmonic atomic force microscopy reveal Syk-dependent changes in microtubule stability mediated by MAP1B. Biochemistry 54:60-68. https://doi.org/10.1021/bi500325n

Luangdilok S, Box C, Patterson L, Court W, Harrington K, Pitkin L, Rhŷs-Evans P, O-charoenrat P, Eccles S (2007) Syk tyrosine kinase is linked to cell motility and progression in squamous cell carcinomas of the head and neck. Cancer Res 67(16):7907-7916

McShane LM, Altman DG, Sauerbrei W. Taube SE, Gion M, Clark GM, Statistics Subcommittee of the NCI-EORTC Working Group on Cancer Diagnostics (2005) REporting recommendations for tumour MARKer prognostic studies (REMARK). Br J Cancer 93:387-391

Mohammad DK, Nore BF, Gustafsson MO, Mohamed AJ, Smith CIE (2016) Protein kinase B (AKT) regulates SYK activity and shuttling through 14-3-3 and importin 7. Int J Biochem Cell Biol 78:63-74. https://doi.org/10.1016/j.biocel.2016.06.024

Moroni M, Soldatenkov V, Zhang L, Zhang Y, Stoica G, Gehan E, Rashidi B, Singh B, Ozdemirli M, Mueller SC (2004) Progressive loss of Syk and abnormal proliferation in breast cancer cells. Cancer Res 64(20):7346-7354

Nakashima H, Natsugoe S, Ishigami S, Okumura H, Matsumoto M, Hokita S, Aikou T (2006) Clinical significance of nuclear expression of spleen tyrosine kinase (Syk) in gastric cancer. Cancer Lett 236(1):89-94

Ogane S, Onda T, Takano N, Yajima T, Uchiyama T, Shibahara T (2009) Spleen tyrosine kinase as a novel candidate tumor suppressor gene for human oral squamous cell carcinoma. Int J Cancer 124(11):2651-2657. https://doi.org/10.1002/ijc.24237

Orr GA, Verdier-Pinard P, McDaid H, Horwitz SB (2003) Mechanisms of Taxol resistance related to microtubules. Oncogene 22(47):7280-7295

Ou Y, Zheng X, Gao Y, Shu M, Leng T, Li Y, Yin W, Zhu W, Huang Y, Zhou Y et al (2014) Activation of cyclic AMP/PKA pathway inhibits bladder cancer cell invasion by targeting MAP4-dependent microtubule dynamics. Urol Oncol 32(1):47.e21-47.e28. https ://doi.org/10.1016/j.urolonc.2013.06.017

Peng CL, Zhang Y, Sun QF, Zhao YP, Hao YT, Zhao XG, Cong B (2013) Inhibitory effects of syk transfection on lung cancer cell invasion. Asian Pac J Cancer Prev 14(5):3001-3003

Poruchynsky MS, Giannakakou P, Ward Y, Bulinski JC, Telford WG, Robey RW, Fojo T (2001) Accompanying protein alterations in malignant cells with a microtubule-polymerizing drug-resistance phenotype and a primary resistance mechanism. Biochem Pharmacol 62(11):1469-1480

Prinos P, Garneau D, Lucier JF, Gendron D, Couture S, Boivin M, Brosseau JP, Lapointe E, Thibault P, Durand M et al (2011) Alternative splicing of Syk regulates mitosis and cell survival. Nat Struct Mol Biol 18(6):673-679. https://doi.org/10.1038/nsmb.2040

Singh R, Masuda ES, Payan DG (2012) Discovery and development of spleen tyrosine kinase (Syk) inhibitors. J Med Chem 55(8):36143643. https://doi.org/10.1021/jm201271b
Storr SJ, Safuan S, Woolston CM, Abdel-Fatah T, Deen S, Chan SY, Martin SG (2012) Calpain-2 expression is associated with response to platinum based chemotherapy, progression-free and overall survival in ovarian cancer. J Cell Mol Med 16(10):24222428. https://doi.org/10.1111/j.1582-4934.2012.01559.x

Udyavar AR, Hoeksema MD, Clark JE, Zou Y, Tang Z, Li Z, Li M, Chen H, Statnikov A, Shyr Y et al (2013) Co-expression network analysis identifies Spleen Tyrosine Kinase (Syk) as a candidate oncogenic driver in a subset of small-cell lung cancer. BMC Syst Biol 7(Suppl 5):S1. https://doi.org/10.1186/1752-0509-7-S5-S1

Venables JP, Klinck R, Bramard A, Inkel L, Dufresne-Martin G, Koh C, Gervais-Bird J, Lapointe E, Froehlich U, Durand M et al (2008) Identification of alternative splicing markers for breast cancer. Cancer Res 68(22):9525-9531. https://doi.org/10.1158/00085472.CAN-08-1769

Wang L, Duke L, Zhang PS, Arlinghaus RB, Symmans WF, Sahin A, Mendez R, Dai JL (2003) Alternative splicing disrupts a nuclear localization signal in spleen tyrosine kinase that is required for invasion suppression in breast cancer. Cancer Res 63(15):4724-4730

Wang L, Devarajan E, He J, Reddy SP, Dai JL (2005) Transcription repressor activity of spleen tyrosine kinase mediates breast tumor suppression. Cancer Res 65(22):10289-10297

Wei W, Birrer MJ (2015) Spleen tyrosine kinase confers paclitaxel resistance in ovarian cancer. Cancer Cell 28(1):7-9. https://doi. org/10.1016/j.ccell.2015.06.008

Yanagi S, Inatome R, Takano T, Yamamura H (2001) Syk expression and novel function in a wide variety of tissues. Biochem Biophys Res Commun 288(3):495-498

Yu Y, Gaillard S, Phillip JM, Huang TC, Pinto SM, Tessarollo NG, Zhang Z, Pandey A, Wirtz D, Ayhan A et al (2015) Inhibition of spleen tyrosine kinase potentiates paclitaxel-induced cytotoxicity in ovarian cancer cells by stabilizing microtubules. Cancer Cell 28(1):82-96

Yuan Y, Wang J, Li J, Wang L, Li M, Yang Z, Zhang C, Dai JL (2006) Frequent epigenetic inactivation of spleen tyrosine kinase gene in human hepatocellular carcinoma. Clin Cancer Res 12(22):6687-6695

Zhang X, Shrikhande U, Alicie BM, Zhou Q, Geahlen RL (2009) Role of the protein tyrosine kinase Syk in regulating cell-cell adhesion and motility in breast cancer cells. Mol Cancer Res 7(5):634-644

Zhang S, Deen S, Storr SJ, Chondrou PS, Nicholls H, Yao A, Rungsakaolert P, Martin SG (2018) Calpain system protein expression and activity in ovarian cancer. J Cancer Res Clin Oncol. https:// doi.org/10.1007/s00432-018-2794-2 (Epub ahead of print)

Zhou F, Hu J, Ma H, Harrison ML, Geahlen RL (2006) Nucleocytoplasmic trafficking of the Syk protein tyrosine kinase. Mol Cell Biol 26(9):3478-3491

Publisher's Note Springer Nature remains neutral with regard to jurisdictional claims in published maps and institutional affiliations. 